\title{
Importance of rostral ventrolateral medulla neurons in determining efferent sympathetic nerve activity and blood pressure
}

\author{
Hiroo Kumagai ${ }^{1}$, Naoki Oshima ${ }^{1}$, Tomokazu Matsuura ${ }^{2}$, Kamon Iigaya ${ }^{2}$, Masaki Imai ${ }^{2}$, Hiroshi Onimaru ${ }^{3}$, \\ Katsufumi Sakata ${ }^{2}$, Motohisa Osaka ${ }^{4}$, Toshiko Onami ${ }^{2}$, Chie Takimoto ${ }^{2}$, Tadashi Kamayachi ${ }^{2}$, Hiroshi Itoh ${ }^{2}$ \\ and Takao Saruta ${ }^{2}$
}

Accentuated sympathetic nerve activity (SNA) is a risk factor for cardiovascular events. In this review, we investigate our working hypothesis that potentiated activity of neurons in the rostral ventrolateral medulla (RVLM) is the primary cause of experimental and essential hypertension. Over the past decade, we have examined how RVLM neurons regulate peripheral SNA, how the sympathetic and renin-angiotensin systems are correlated and how the sympathetic system can be suppressed to prevent cardiovascular events in patients. Based on results of whole-cell patch-clamp studies, we report that angiotensin II (Ang II) potentiated the activity of RVLM neurons, a sympathetic nervous center, whereas Ang II receptor blocker (ARB) reduced RVLM activities. Our optical imaging demonstrated that a longitudinal rostrocaudal column, including the RVLM and the caudal end of ventrolateral medulla, acts as a sympathetic center. By organizing and analyzing these data, we hope to develop therapies for reducing SNA in our patients. Recently, 2-year depressor effects were obtained by a single procedure of renal nerve ablation in patients with essential hypertension. The ablation injured not only the efferent renal sympathetic nerves but also the afferent renal nerves and led to reduced activities of the hypothalamus, RVLM neurons and efferent systemic sympathetic nerves. These clinical results stress the importance of the RVLM neurons in blood pressure regulation. We expect renal nerve ablation to be an effective treatment for congestive heart failure and chronic kidney disease, such as diabetic nephropathy. Hypertension Research (2012) 35, 132-141; doi:10.1038/hr.2011.208; published online 15 December 2011

Keywords: patch-clamp technique; sympathetic nervous system; congenic rat; RVLM neurons; optical imaging

\section{ACCENTUATED SYMPATHETIC NERVE ACTIVITY (SNA)} INDUCED BY ROSTRAL VENTROLATERAL MEDULLA (RVLM) NEURONS IS A PRIMARY CAUSE OF ESSENTIAL HYPERTENSION

Potentiated SNA is considered to be a robust risk factor for cardiovascular events, such as cerebral infarction and myocardial infarction. ${ }^{1}$ Peripheral SNA is accentuated in patients with hypertension, congestive heart failure, diabetes, obesity and chronic kidney diseases. At least $50 \%$ of hypertensive patients show potentiated SNA. ${ }^{2,3}$ As an increase in SNA precedes the onset of hypertension, ${ }^{4-6}$ we hypothesize that potentiation of the sympathetic nervous system (SNS) is the primary cause of hypertension. ${ }^{7,8}$ The precise mechanisms of the central and peripheral SNSs must be understood for adequate treatment and prevention of cardiovascular events.

The RVLM oblongata region contains neurons that has a key role in determining peripheral sympathetic vasomotor tone and blood pres- sure (BP) (Figure 1). ${ }^{4-10}$ The increased activity of RVLM neurons is transmitted to the intermediolateral cell column (IML) at each level of the spinal cord, where peripheral sympathetic nerves to the heart, arterioles and kidneys are activated, thus increasing BP. For this reason, RVLM neurons are referred to as a sympathetic nervous center or cardiovascular center. We hypothesize that accentuated activity of RVLM neurons is the primary cause of essential hypertension.

When BP is suddenly elevated, the activities of the arterial baroreceptors and cranial nerves IX and X (vagal afferent nerves), and the neuronal activity of the caudal VLM (CVLM) are increased via the nucleus tractus solitarius. Since the synaptic transmission from CVLM neurons to RVLM neurons is mediated by inhibitory amino acid GABA, the neuronal activity of the RVLM is suppressed, and so are the activities of IML neurons and efferent sympathetic nerves, and thus BP is decreased. ${ }^{7-10}$ This pathway is known as the arterial (highpressure) baroreflex. The CVLM is also a critical region for tonic and

${ }^{1}$ Department of Nephrology, National Defense Medical College, Tokorozawa, Japan; ${ }^{2}$ Department of Internal Medicine, Division of Endocrinology, Metabolism, and Nephrology, Keio University School of Medicine, Tokyo, Japan; ${ }^{3}$ Department of Physiology, Showa University School of Medicine, Tokyo, Japan and ${ }^{4}$ Department of Mathematics, Nippon Veterinary and Life Science University, Tokyo, Japan

Correspondence: Dr H Kumagai, Department of Nephrology, National Defense Medical College, 3-2 Namiki, Tokorozawa, Saitama 359-8513, Japan.

E-mail: hkumagai@ndmc.ac.jp

Received 22 April 2011; revised 17 October 2011; accepted 27 October 2011; published online 15 December 2011 


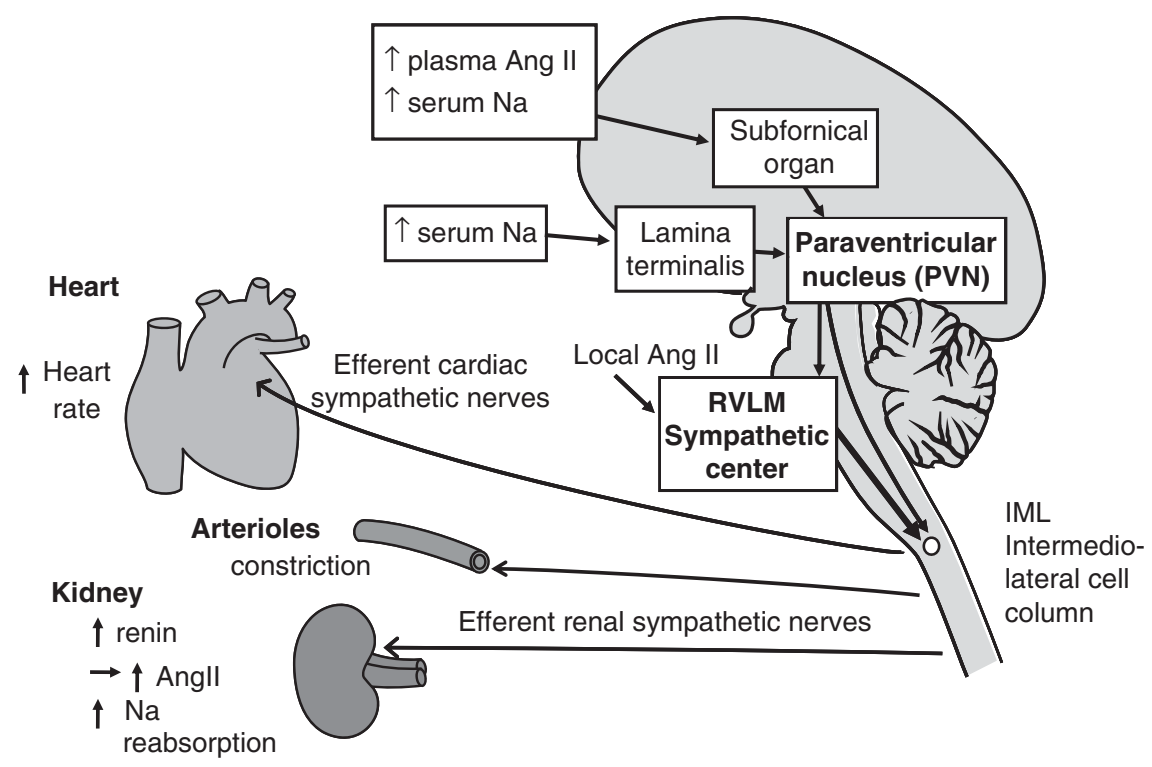

Figure 1 Schematic drawing of the central and peripheral sympathetic nervous systems (original drawing by Kumagai). Increased activity of the rostral ventrolateral medulla (RVLM) neurons is transmitted to the intermediolateral (IML) cell column of the spinal cord, where peripheral sympathetic nerves to the heart, arterioles and kidneys are activated, thus increasing blood pressure (BP). Potentiated sensitivity of the subfornical organ to plasma angiotensin II (Ang II), and that of the subfornical organ and the lamina terminalis to serum $\mathrm{Na}$, increases the efferent sympathetic activity and BP through the activation of the paraventricular nucleus (PVN) and the RVLM neurons in essential hypertension. A full color version of this figure is available at the Hypertension Research journal online.

reflex control of the SNS, as CVLM neurons send tonically inhibitory signals to RVLM neurons. ${ }^{10,11}$ Baroreceptor-activated GABAergic neurons have been identified in the CVLM region using extracellular recordings. ${ }^{12-15}$

\section{ANGIOTENSIN II (ANG II) ACTIVATES AND ANG II RECEPTOR BLOCKER (ARB) SUPPRESSES THE RVLM NEURONS}

We previously reported the impairment of the baroreflex function in hypertensive animals, based on recordings of renal sympathetic nerve activity (RSNA) and vagal afferent nerve activity in conscious rabbits and rats. ${ }^{16,17}$ Candesartan, an ARB, improved the impaired baroreflex function in conscious rats with congestive heart failure. ${ }^{18}$ Earlier studies utilized microinjection of AngII and an ARB into the RVLM region. Ang II microinjected in the RVLM increased $\mathrm{BP}$ and heart rate in normotensive and hypertensive rats. ${ }^{19}$ The effects of Ang II on RVLM neurons have been examined using patch-clamp recordings in a slice preparation. ${ }^{20}$ GABA- and glycine-mediated inhibitory postsynaptic potentials were reported in RVLM neurons of neonatal rats in vitro. ${ }^{21}$ However, the precise neuronal mechanisms by which RVLM neurons regulate peripheral SNA and BP and those by which RVLM neurons are regulated by Ang II have not been fully elucidated.

We performed whole-cell patch-clamp technique (intracellular recording, current clamp) using an isolated brainstem-spinal cord preparation, in which baroreceptor afferent and efferent preganglionic nerves are preserved. ${ }^{22}$ We found three types of firing patterns in the rat RVLM neurons: regularly firing neurons, irregularly firing neurons and silent neurons.

We then compared the electrophysiological properties of single RVLM neurons from neonatal Wistar-Kyoto (WKY) rats $(n=54)$ and spontaneously hypertensive rats (SHR, $n=89) .^{23,24}$ The resting membrane potential of irregularly firing RVLM neurons in SHR was significantly less negative (more excitable) than that in WKY $(P<0.05)$. The firing rate of irregularly firing neurons was significantly faster in SHR $(3.2 \pm 0.2 \mathrm{~Hz})$ than in WKY $(2.0 \pm 0.2 \mathrm{~Hz})$,

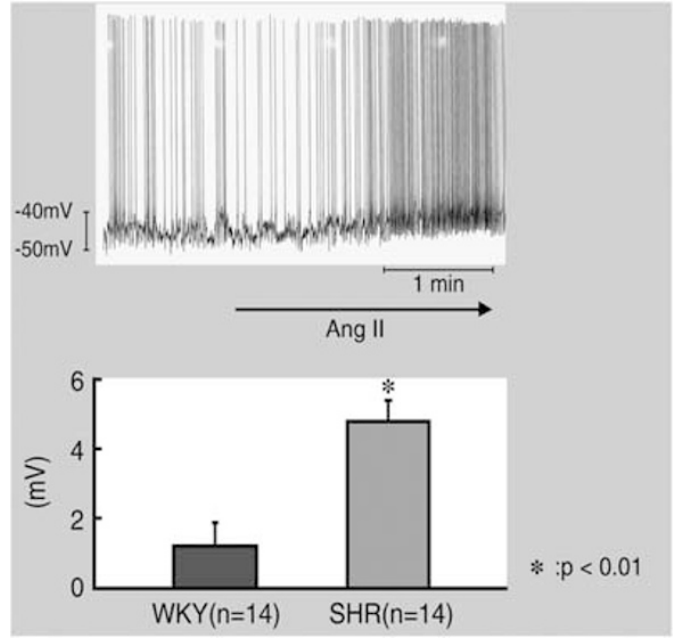

Figure 2 Top; whole-cell patch-clamp recording of membrane depolarization and increase in firing rate of an RVLM bulbospinal neuron during Ang II $\left(6 \mathrm{mmol}^{-1}\right)$ superfusion in brain stem-spinal cord preparation of neonatal SHR. Bottom; average changes in membrane potential of RVLM bulbospinal neurons. Values are the means \pm s.e.m. ${ }^{*} P<0.05$ vs. before superfusion. ${ }^{23}$ A full color version of this figure is available at the Hypertension Research journal online.

whereas the firing rates of regularly firing neurons did not differ between SHR $(5.3 \pm 0.4 \mathrm{~Hz})$ and WKY $(4.2 \pm 0.3 \mathrm{~Hz})$.

One to two minutes after the start of superfusion with $6 \mu \mathrm{moll}^{-1}$ of Ang II, the RVLM bulbospinal neurons in SHR depolarized and the firing rate increased (Figure 2). The depolarization of RVLM neurons in SHR was $+5.4 \pm 1.1 \mathrm{mV}$, which was a significantly larger depolarization than that in WKY rats. The increase in the firing rate was also faster in SHR than in WKY. 


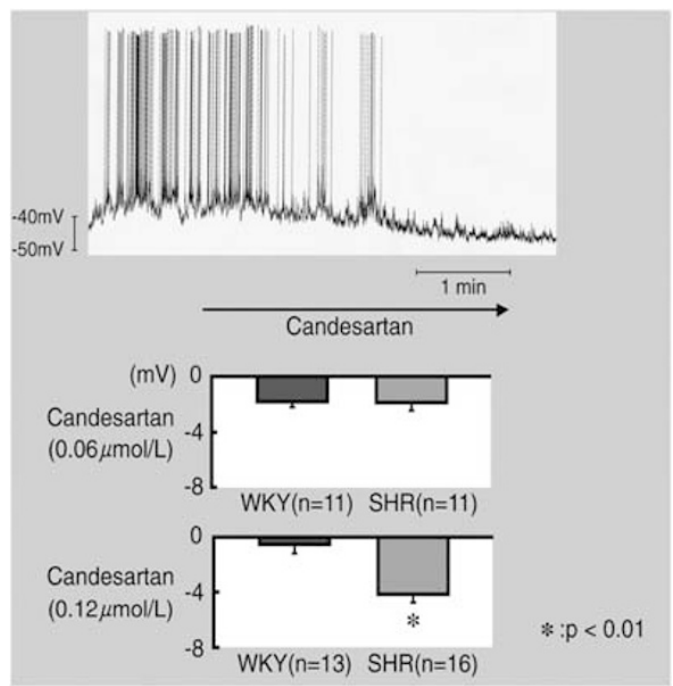

Figure 3 Top; whole-cell patch-clamp recording of membrane hyperpolarization and decrease in the firing rate of an RVLM bulbospinal neuron during candesartan $\left(0.12 \mathrm{mmoll}^{-1}\right)$ superfusion in an SHR preparation. Bottom; average changes in membrane potential of RVLM bulbospinal neurons. The changes in membrane potential during candesartan superfusion were significant when compared with the values obtained before superfusion in SHR, but not in WKY rats. ${ }^{23} \mathrm{~A}$ full color version of this figure is available at the Hypertension Research journal online.

On the other hand, superfusion with candesartan $\left(0.12 \mu \mathrm{moll}^{-1}\right)$ gradually hyperpolarized the RVLM bulbospinal neurons in SHR and reduced the firing rate (Figure 3 ). The average amplitude of hyperpolarization of RVLM neurons in SHR was significantly larger than that in WKY. During superfusion with candesartan, the firing rate of the irregularly firing neurons in SHR decreased significantly, whereas the firing rate in WKY did not decrease.

Our results suggest that endogenously generated Ang II (presumably produced by astrocytes but not by neurons) binds to the $\mathrm{AT}_{1}$ receptors on RVLM neurons, and that this neuropeptide tonically activates the RVLM neurons in SHR. Ang II increased sympathetic outflow via $\mathrm{AT}_{1} \mathrm{R}$ in animals with heart failure. ${ }^{25}$ Candesartan microinjected into the RVLM region reduced the BP, HR and RSNA in normotensive rats in vivo. ${ }^{26}$

Tsuchihashi et al. ${ }^{27}$ demonstrated that, after either imidapril or candesartan was given orally to SHR for a period of 1 month, the pressor response to Ang II, which was microinjected into the RVLM region, was significantly smaller in candesartan-treated rats than in imidapril-treated rats. That is, candesartan reduces the activity of the RVLM neurons, which are situated behind the blood-brain barrier, even when it is administered peripherally. Therefore, when candesar$\tan$ is administered orally in a clinical setting, it can suppress the activity of RVLM neurons, and this sympathoinhibitory mechanism is responsible for the antihypertensive effect of candesartan.

Both potentiated RVLM neurons and RSNA induce renin release and Ang II production (Figure 1). Our whole-cell patch-clamp studies showed that Ang II superfusion activated the RVLM neurons, whereas ARB suppressed the RVLM neurons. ${ }^{23}$ Therefore, we were able to directly demonstrate the occurrence of 'a vicious cycle' between the SNS and the renin-angiotensin system (RAS). To interrupt this vicious cycle and prevent cardiovascular events in our patients, we should choose drugs, such as ARBs, that suppress both the SNS and the RAS.

\section{ANGII ENHANCES GLUTAMATE RELEASE FROM PRESYNAPTIC SITES TO RVLM NEURONS, EXAMINED BY VOLTAGE-CLAMP}

To examine the mechanisms by which Ang II activates RVLM neurons in relation to electrical currents, Imai and Kaneda (unpublished data, 2005) of our laboratory attempted to identify excitatory postsynaptic currents (EPSCs) in RVLM neurons using the voltage-clamp technique. As Sumners et al. ${ }^{28,29}$ previously demonstrated that a decrease in $\mathrm{K}$ current is an underlying postsynaptic mechanism of Ang II-induced depolarization in RVLM neurons, we tried to seek a presynaptic mechanism, using a brainstem slice preparation.

We found that RVLM neurons simultaneously received two types of synaptic inputs at the holding potential of $-70 \mathrm{mV}$, that is, EPSCs and inhibitory PSCs. EPSCs decayed quickly and were inhibited by glutamate receptor (non-NMDA) blocker, CNQX $\left(10 \mu \mathrm{moll}^{-1}\right)$. In contrast, inhibitory PSCs decayed slowly and were inhibited by GABA type A receptor blocker, SR-95531 $\left(30 \mu \mathrm{moll}^{-1}\right)$.

Superfusion with $2 \mu \mathrm{moll}^{-1}$ of Ang II produced a sustained inward current $(25 \pm 4 \mathrm{pA})$ and significantly increased the frequency (fourfold) and amplitude (twofold) of the EPSCs (holding potential $-40 \mathrm{mV}$ ) under the $\mathrm{GABA}_{\mathrm{A}}$ blockade. We speculate that this inward current shown by the voltage clamp is an underlying mechanism for significant depolarization examined with our current clamp study. ${ }^{23}$ CNQX abolished the Ang II-evoked increase in EPSCs. Therefore, our data suggest that Ang II presynaptically enhances glutamatergic inputs to the RVLM neurons, whereas this peptide postsynaptically produces an inward current.

\section{ESSENTIAL HYPERTENSIVE PATIENTS WITH ACCENTUATED RAS}

On the basis of our experiments using the brainstem-spinal cord preparation, we speculate about the pressor mechanism in a subgroup of essential hypertensive patients with accentuated RAS (Figure 1). The subfornical organ in the forebrain can detect increases in the plasma concentration of Ang II because of lack of a blood-brain barrier. ${ }^{30-32}$ In essential hypertensive patients with accentuated RAS, the Ang II-induced signals from the stimulated subfornical organ are transmitted to the paraventricular nucleus neurons in the hypothalamus, thus activating the RVLM neurons and peripheral SNA, and raising the BP. Ang II decreases the tonic sympathoinhibitory effect of GABA within the paraventricular nucleus. ${ }^{33}$ Therefore, the subfornical organ can translate the elevated plasma Ang II into an increase in peripheral SNA via the paraventricular nucleus and RVLM neurons.

On the other hand, circulating Ang II cannot reach the RVLM neurons directly, as these neurons are situated within the blood-brain barrier. We speculate that local Ang II generated by the surrounding astrocytes stimulates the RVLM neurons (Figure 1).

\section{ESSENTIAL HYPERTENSIVE PATIENTS WITH HIGH SALT SENSITIVITY}

In subjects with normal salt sensitivity, a high serum concentration of sodium (Na) stimulates the cardiac (low-pressure) baroreflex and should reduce RSNA and Na re-absorption at proximal tubules. The subfornical organ and the organum vasculosum of the lamina terminalis in the forebrain detect increases in serum $\mathrm{Na}$ concentration and osmolality ${ }^{30,31,34-36}$ (Figure 1). The increase in the electrophysiological activities of the subfornical organ and the lamina terminalis stimulates the neurons in the paraventricular nucleus, thus activating the RVLM neurons and peripheral SNA. In other words, these organs translate increased serum Na into sympathoexcitation (Figure 1), so that RSNA is not suppressed and $\mathrm{Na}$ re-absorption continues. Therefore, the 
potentiated sensitivity of the subfornical organ and the lamina terminalis to serum $\mathrm{Na}$ concentration is a critical factor in the elevated $\mathrm{BP}$ of patients with high salt sensitivity.

\section{OTHER FACTORS THAT AFFECT THE ELECTROPHYSIOLOGICAL PROPERTIES OF RVLM NEURONS}

Hirooka and colleagues ${ }^{37,38}$ have examined the effects of reactive oxygen species (ROS, oxidative stress) on RVLM neurons and central sympathetic outflow. ROS production is increased in the RVLM of hypertensive rats compared with normotensive rats and this increased ROS enhances the central sympathetic outflow and raises BP. ${ }^{39-41}$ $\mathrm{Cu}-\mathrm{Zn}$-superoxide dismutase delivered by adenovirus reduces ROS in the RVLM and lowers peripheral sympathetic activity and systemic BP of hypertensive rats. ${ }^{42}$

Controversy remains as to whether endogenous nitric oxide (NO) decreases SNA. Some reports show that NO decreased the activities of RVLM neurons and sympathetic outflow. ${ }^{43,44}$ In contrast, Kimura et $a l .{ }^{45}$ reported that NO produced by inducible NOS in the RVLM contributed to high BP of SHR. Endothelin may affect the property of RVLM neurons and sympathetic activity. ${ }^{46}$

The interaction between the sympathetic system and respiratory system has been the focus of several studies. The respiratory system modifies the SNS in the hypothalamus and the nucleus tractus solitarius. ${ }^{47,48}$ Iigaya et al. ${ }^{49}$ recently demonstrated that, in response to environmental stressors, respiratory neurons modulate the neurons in the periaqueductal gray of the midbrain and RSNA.

\section{QUANTITATIVE TRAIT LOCUS (QTL) ON CHROMOSOME 1 AFFECTS THE ELECTROPHYSIOLOGICAL CHARACTERISTICS OF RVLM NEURONS}

Genetic factors that induce essential hypertension have been examined using genome-wide linkage analysis. A QTL that is closely linked to hypertension was found on chromosome 1 in stroke-prone SHR
(SHRSP). ${ }^{50-52}$ Based on this finding, Nabika and colleagues ${ }^{53-55}$ at Shimane University established two congenic rat strains through 10 generations of repeated backcrossing. The 'WKYpch1.0 congenic rat' was created by introgressing 'the small QTL region $(60-\mathrm{cM})$ for BP on rat chromosome 1 from SHRSP/Izm' into WKY/Izm rats (Figure 4). Meanwhile, the 'SHRSPwch1.0 congenic rat' was created by introgressing 'the same QTL on rat chromosome 1 from WKY/Izm rats' into SHRSP/Izm.

Basal values of systolic BP and heart rate were larger in WKYpch1.0 congenic rats than those in WKY (Figure 4). Neonatal chemical sympathectomy abolished the exaggerated responses in BP and urinary excretion of norepinephrine (NE) in WKYpch1.0 congenic rats. ${ }^{53}$ To determine whether basal characteristics of RVLM neurons and responses to Ang II are regulated by genetic factors, we examined whether the intermediate phenotype of the QTL for hypertension was hyperactivity of the RVLM neurons. ${ }^{56}$ Whole-cell patch-clamping of RVLM neurons was performed from neonatal WKY rats, WKYpch1.0 congenic rats, SHRSP and SHRSPwch1.0 congenic rats. Changes in membrane potential during Ang II superfusion $\left(6 \mu \mathrm{moll}^{-1}\right)$ were then determined.

The resting membrane potential of regularly firing RVLM neurons from WKY rats was $-55.4 \mathrm{mV}$, whereas that of neurons from WKY congenic rats was $-46.4 \mathrm{mV}$. Thus, the resting membrane potential of WKY congenic rats was significantly less negative (more excitable). The firing rate of RVLM neurons from WKY rats was $2.7 \mathrm{~Hz}$, whereas that of WKY pch1.0 congenic rats was $3.3 \mathrm{~Hz}$.

The amplitude of depolarization induced by Ang II superfusion in RVLM neurons from WKYpch1.0 rats was significantly larger than that from WKY rats (Figure 5). On the other hand, the depolarization induced by Ang II from SHRSPwch1.0 was significantly smaller than that of neurons from SHRSP. Therefore, RVLM neurons from rats with a QTL originating from SHRSP (WKYpch1.0 and SHRSP) showed a significantly larger depolarization in response to Ang II superfusion than RVLM neurons from rats with a QTL originating from WKY (WKY and SHRSPwch1.0).

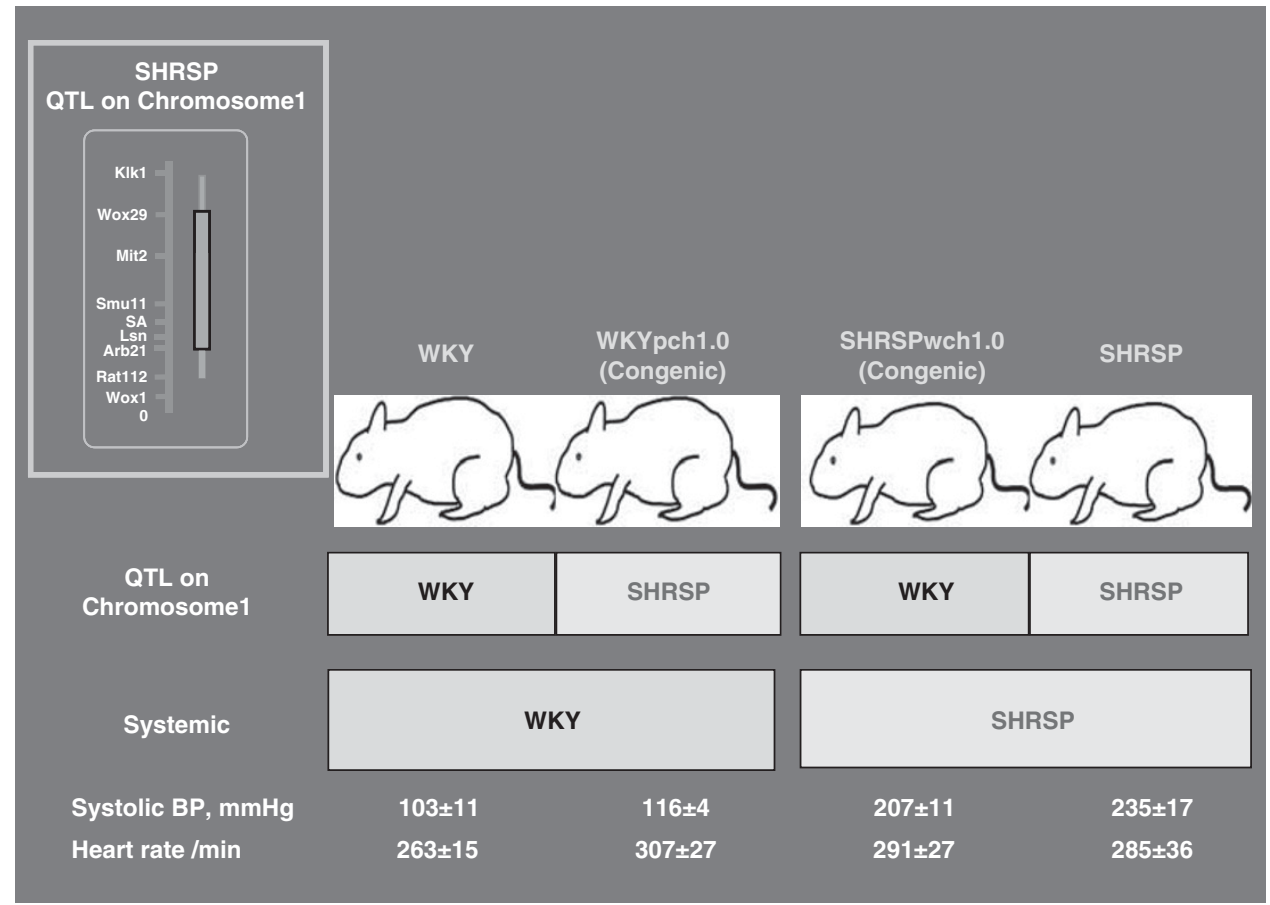

Figure 4 Genotypic and phenotypic (BP and heart rate) characteristics of two strains of congenic rats (WKYpch1.0 rats and SHRSPwch1.0) that were developed by Professor Nabika et al. (reproduced from ligaya et al. ${ }^{56}$ ). A full color version of this figure is available at the Hypertension Research journal online. 
a

WKY

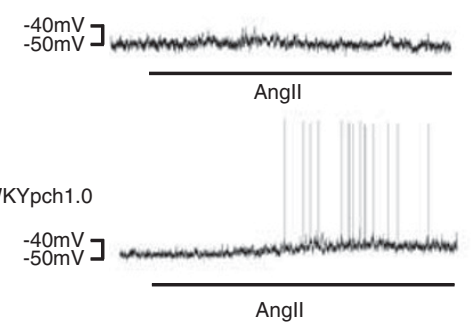

SHRSPwch1.0

$$
-40 \mathrm{mV}
$$

$-50 \mathrm{mV}$

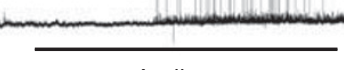

Angll

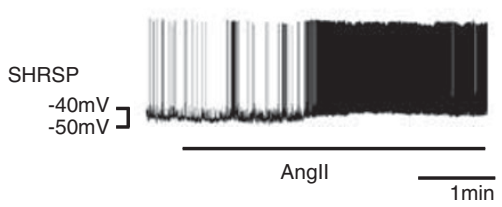

b

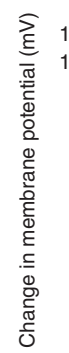

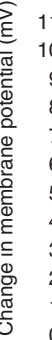

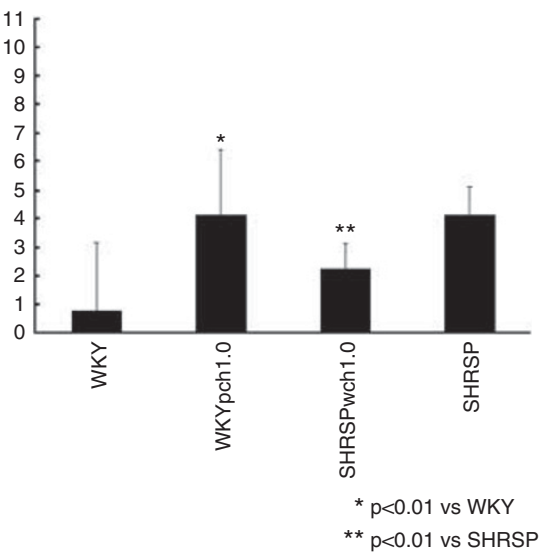

Figure 5 Depolarization of a single RVLM neuron from rats carrying the chromosome 1 QTL (quantitative trait locus) of SHRSP (WKYpch1.0 and SHRSP) in response to superfusion with Ang II $\left(6 \mu \mathrm{moll}^{-1}\right)$ was significantly larger than that from rats without the QTL (cited from ligaya et al. ${ }^{56}$ ). (a) Representative traces from each strain. (b) Changes in membrane potential (depolarization) of the RVLM neurons in response to Ang II superfusion (the mean \pm s.d. of eight neurons from different rats of each strain).

These data suggest that the intermediate phenotype of the QTL for BP on rat chromosome 1 corresponds to hyperactivity of the RVLM neurons in response to Ang II. Our data also imply that electrophysiological characteristics of RVLM neurons in rats are affected by a relatively short QTL on chromosome 1 and that genetic factors are important in determining peripheral SNA and systemic BP. ${ }^{56}$

As WKYpch1.0 congenic rats show exaggerated sympathetic responses to various stressors, ${ }^{54,55}$ we hypothesize that genes in the chromosome 1 QTL will affect sympathetic responsiveness to stress through an Ang II-mediated system in the RVLM. In support of our hypothesis, previous data show that hyper-responsiveness of BP and RSNA to air-jet stress in WKYpch1.0 rats was inhibited by intracerebroventricular injection of candesartan. ${ }^{57}$

\section{OPTICAL IMAGING REVEALED MONOSYNAPTIC PROJECTION FROM THE CAUDAL END OF VENTROLATERAL MEDULLA (CEVLM) TO THE SPINAL CORD}

The connection between RVLM and IML in the spinal cord has been demonstrated by experiments in which virus and chemical tracers, such as pseudorabies virus, horse radish peroxidase and wheat germ agglutinin, are injected in the adrenal gland and sympathetic ganglia. ${ }^{58-60}$

We performed optical imaging to test whether neurons in the CeVLM, like the RVLM neurons, project monosynaptically (axonally) to neurons in the IML at the level of Th2. ${ }^{61}$ In most of the experiments, the preparations were superfused with a low- $\mathrm{Ca}^{2+}$ high- $\mathrm{Mg}^{2+}$ solution to block synaptic transmission and to exclude the ascending monosynaptic and polysynaptic projections and descending polysynaptic projections, and to detect the descending monosynaptic projections alone.

The brainstem-spinal cord preparation was incubated for 40-50 min in a standard solution containing fluorescent voltagesensitive dye (left panel, Figure 6). The preparation was then placed in a perfusion chamber mounted on a fluorescence microscope (BX50WIF-2;
Olympus). Neuronal activity in the preparation was detected as a change in fluorescence of the voltage-sensitive dye using an optical imaging apparatus (MiCAM01; Brain Vision, Tsukuba, Japan). ${ }^{61,62} \mathrm{We}$ obtained optical visualization (depolarizing responses) in the medulla oblongata in response to electrical stimulation of the IML at the level of Th2, where the efferent sympathetic nerve to the heart exits. ${ }^{63}$ Most recordings were performed with an acquisition time of $10 \mathrm{~ms}$.

As shown in Figure 7, the IML stimulation during a low- $\mathrm{Ca}^{2+}$ superfusion induced depolarizing responses in the longitudinal column of the rostro-caudal VLM, including the RVLM and the CeVLM regions. The latency between IML stimulation and the start of antidromic depolarization in the CeVLM was $28 \pm 7 \mathrm{~ms}$. Furthermore, when observed on the cross section, the IML stimulation induced depolarizing responses in restricted regions at the level of the CeVLM (Figure 8).

Finally, to examine whether CeVLM neurons are actually involved in the cardiovascular system, IML neurons at the Th2 level were recorded using the patch-clamp technique, and glutamate $\left(1 \mathrm{mmoll}^{-1}, 10 \mu \mathrm{l}\right)$ was applied locally to the CeVLM region, after removing the RVLM region. The local application of glutamate to the CeVLM increased the frequency of excitatory postsynaptic potentials and induced significant depolarization of the IML neurons.

Contrary to conventional conception, ${ }^{4}$ our optical imaging studies have demonstrated that 'a longitudinal rostro-caudal column in the ventrolateral medulla, including the RVLM and the CeVLM regions' gives rise to a monosynaptic projection to the IML. The activation of IML neurons by the topical application of glutamate implies that neurons in the CeVLM send excitatory input to the IML and are involved in sympathetic regulation and BP control. The BP-elevating action of the caudal pressor area is mediated by RVLM neurons. ${ }^{64,65}$ On the other hand, Pilowsky et al. ${ }^{66}$ reported that a new region, the medullo-cervical pressor area, projects to the IML in adult rats and that pressor action of this region is not dependent on the RVLM. As the excitation of IML neurons by glutamate application in the CeVLM was observed without RVLM neurons, the sympathoexcita- 


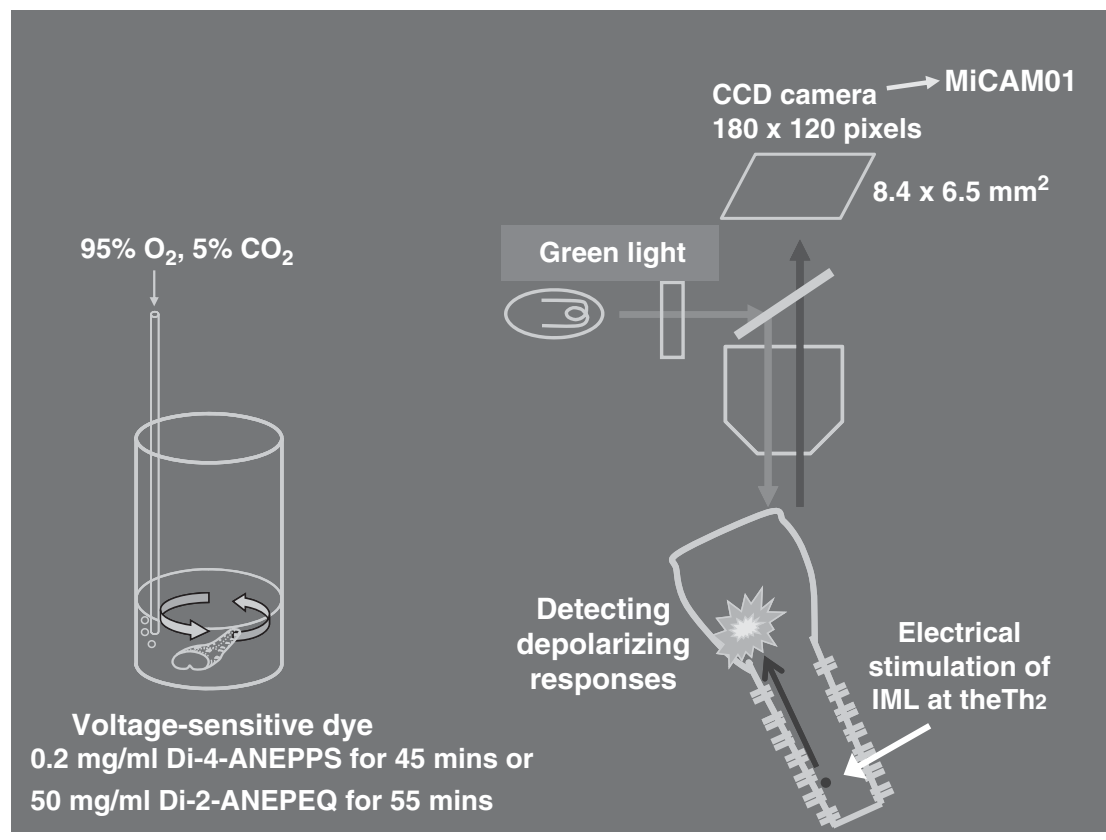

Figure 6 Method of optical imaging for brainstem-spinal cord preparation (reproduced from ligaya et al. ${ }^{61}$ ). Depolarizing responses in the ventrolateral medulla in response to IML stimulation were detected as difference in color. A full color version of this figure is available at the Hypertension Research journal online.

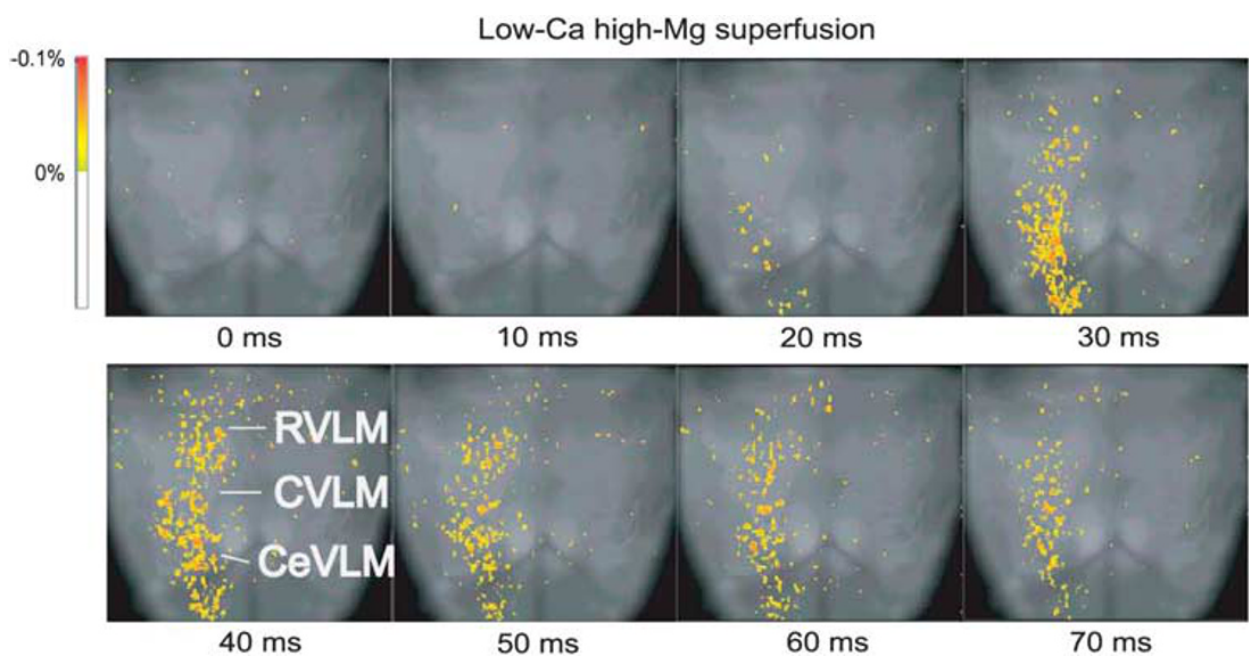

Figure 7 Optical imaging of the ventral surface of the medulla oblongata during superfusion with low- $\mathrm{Ca}^{2+}$, high-Mg ${ }^{2+}$ solution. Depolarizing responses to IML stimulation were detected on the ventral surface at the RVLM and the caudal end of the VLM (CeVLM) region (cited from ligaya et al. ${ }^{61}$ ).

tory action of the CeVLM neurons may be similar to that of the medullo-cervical pressor area.

We also demonstrated the monosynaptic electrical connection by developing simultaneous extracellular recordings of RVLM neurons and whole-cell patch-clamp recordings of IML neurons at the Th2 level. ${ }^{67}$ The data were analyzed using the spike-triggered averaging method.

\section{POTENTIATED SNS IS RESPONSIBLE FOR INCREASED LINEAR CORRELATION AND DECREASED NON-LINEAR CORRELATION BETWEEN RSNA AND BP IN CONSCIOUS SHR}

Contrary to common understanding of homeostasis, the normal cardiovascular system is regulated by non-linear dynamics. ${ }^{68}$ Several diseases, such as congestive heart failure and arrhythmia, are characterized by a reduction in the non-linearity (complexity) of cardiovascular regulation, whereas non-linearity is high in healthy humans and animals. A reduction in non-linear fractal correlation of HR-intervals is shown to be a sensitive predictor of mortality in patients who had suffered myocardial infarction. ${ }^{69}$ In another clinical study, decrease in the non-linear correlation of the HR-intervals preceded ventricular fibrillation or tachycardia. ${ }^{70}$ Although hypertension is an independent risk factor for cardiovascular events and mortality, non-linear correlations among BP, HR, RSNA and renal blood flow (RBF) had not been determined previously in hypertensive humans or animals.

We simultaneously recorded the BP, HR, RSNA and RBF on the same side of the body in conscious rats, ${ }^{71}$ a technique that had been 

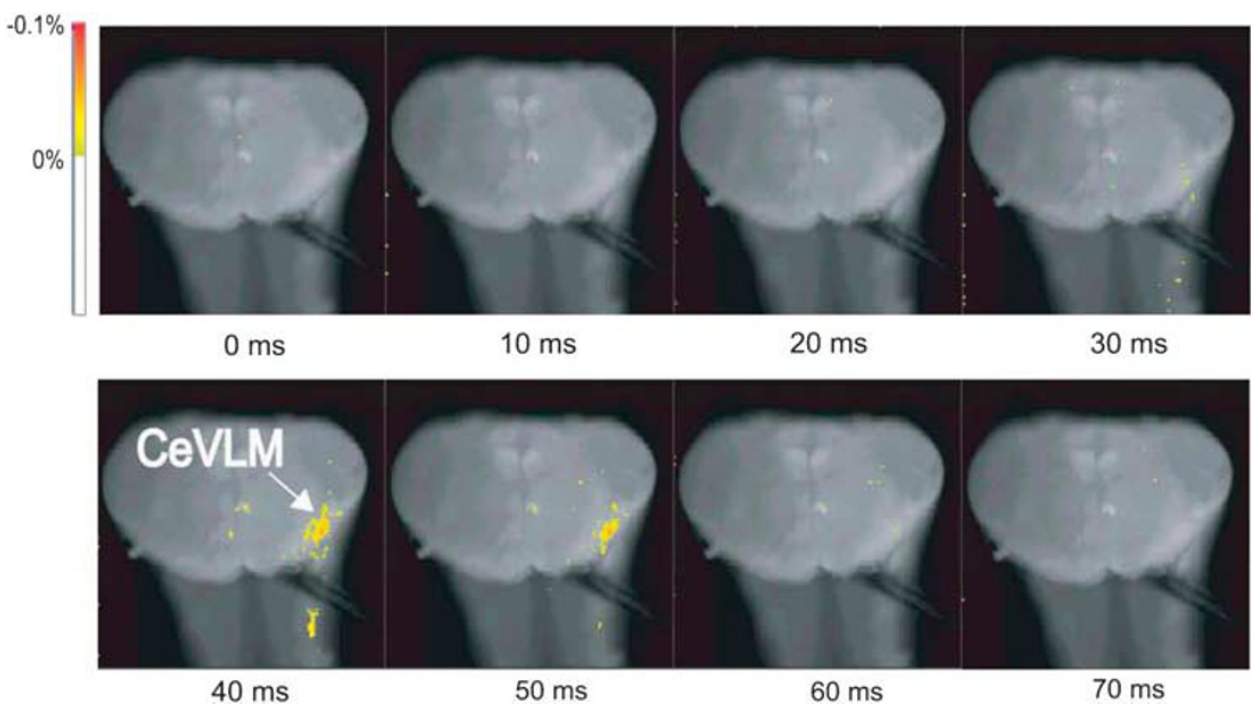

Figure 8 Optical imaging of a cross section at the level of the caudal end of the VLM (CeVLM) during low-Ca ${ }^{2+}$, high-Mg ${ }^{2+}$ superfusion (cited from ligaya et $\left.a l .{ }^{61}\right)$. A depolarizing response to the IML stimulation was detected at the CeVLM region $(n=8)$.

reported to be unsuccessful. We used the coherence of the transfer function (linearity) and the mutual information method (linearity and non-linearity $)^{72}$ to test whether the non-linear correlations among BP, $\mathrm{HR}, \mathrm{RBF}$ and RSNA are reduced in SHR. ${ }^{73}$ We then determined the linearity and non-linearity in SHR treated orally with either candesartan or a vehicle for a period of 2 weeks.

The RSNA value was higher in SHR than in WKY rats, and the coherence peaks of the transfer function were found at 0.05 and $0.80 \mathrm{~Hz}$, that is, below the respiratory- and cardiac-related fluctuations. The coherence of the transfer function from RSNA to $\mathrm{BP}$ was significantly higher in SHR than in WKY. ${ }^{71}$ As the mutual information values (linear and non-linear correlation) were similar in both strains, the non-linear correlation was lower in SHR than in WKY. The time delay values calculated using the mutual information method demonstrated that RSNA preceded BP and RBF by $0.5-1.0 \mathrm{~s}$.

In conscious SHR treated with candesartan, RSNA values and linearity were lower and non-linearity was higher than the values in SHR treated with vehicle. Takimoto et al. ${ }^{74}$ showed that 2 -week oral treatment with candesartan but not amlodipine reduced the RSNA and the linearity of the relation between RSNA and BP in conscious type 1 diabetic rats. Candesartan reduced cardiac SNA determined by metaiodo-benzyl guanidine (MIBG) in heart failure patients. ${ }^{75}$

Possible mechanisms underlying the higher linearity and the lower non-linearity in SHR may include the strong dependence of the cardiovascular systems on only one or two predominant neurohumoral systems (the SNS and RAS), the reduction in the number of neurohumoral systems (NO and baroreflex) or both. In other words, the higher non-linearity in normotensive WKY rats suggests that normal homeostasis of BP depends on various neurohumoral systems and not solely on the SNS.

\section{TWO-YEAR DEPRESSOR EFFECTS OBTAINED BY RENAL NERVE ABLATION IN ESSENTIAL HYPERTENSION}

In 2009 Esler and colleagues ${ }^{76}$ reported a revolutionary therapy for essential hypertensive patients who were resistant to various antihypertensive drugs. Bilateral percutaneous catheter-based renal nerve ablation was performed in 42 patients whose BP was 177/101 $\mathrm{mm} \mathrm{Hg}$ despite taking five antihypertensive drugs. At 9 months after the ablation, 20 patients showed a significant reduction in BP by 24/11 mm Hg.

In 1 of the 42 patients, renal and whole-body NE spillover, an accurate index of peripheral SNA was reduced by $47 \%$, and muscle SNA was suppressed 1 year after the ablation. ${ }^{77}$ These results imply that not only the renal efferent SNA but also the systemic efferent SNA were suppressed.

In recent reports, Esler and colleagues ${ }^{78,79}$ treated 153 patients with catheter-based renal nerve ablation at 19 centers in Australia, Europe, and the United States. Their average baseline office BP was $176 / 98 \mathrm{~mm} \mathrm{Hg}$. At 12 months after ablation, office BP was reduced by $23 / 11 \mathrm{~mm} \mathrm{Hg}$ in 86 patients, and at 24 months the BP was further decreased by $32 / 14 \mathrm{~mm} \mathrm{Hg}$ in 18 patients despite their having undergone only one procedure of renal nerve ablation.

How can the mechanism by which renal nerve ablation reduced the $\mathrm{BP}$ and efferent SNA to other organs be explained? I.v. infusion of high-concentration $\mathrm{NaCl}$ produced a significant pressor effect in baroreceptor-denervated, heminephrectomized rabbits and a prior renal denervation abolished this pressor effect. ${ }^{80}$ This result demonstrates the importance of the renal nerves in raising BP.

Campese et al. ${ }^{81,82}$ showed that kidney injury induced by $10 \%$ phenol (a simulation of chronic kidney disease) increased NE secretion from the posterior hypothalamus and raised systemic BP in rats. Importantly, these increases were prevented by the prior denervation of afferent renal nerves or by a dorsal rhizotomy (destruction of the posterior column of the spinal cord around Th12). These data suggest that information regarding the state of the kidney, such as hypertension, high glucose, ischemia, Ang II and oxidative stress, is transferred via the afferent renal sensory nerves to the hypothalamus, thus stimulating the RVLM neurons and the efferent SNA to the heart, arterioles and kidney, and elevating the BP. Therefore, one can speculate that the catheter-based renal nerve ablation disrupts afferent renal nerves and decreases the neuronal activity of the hypothalamus, thus reducing the activity of the RVLM neurons and efferent SNA.

These data derived from patients and animals strongly imply the importance of the RVLM neurons, as well as afferent renal nerves, in 


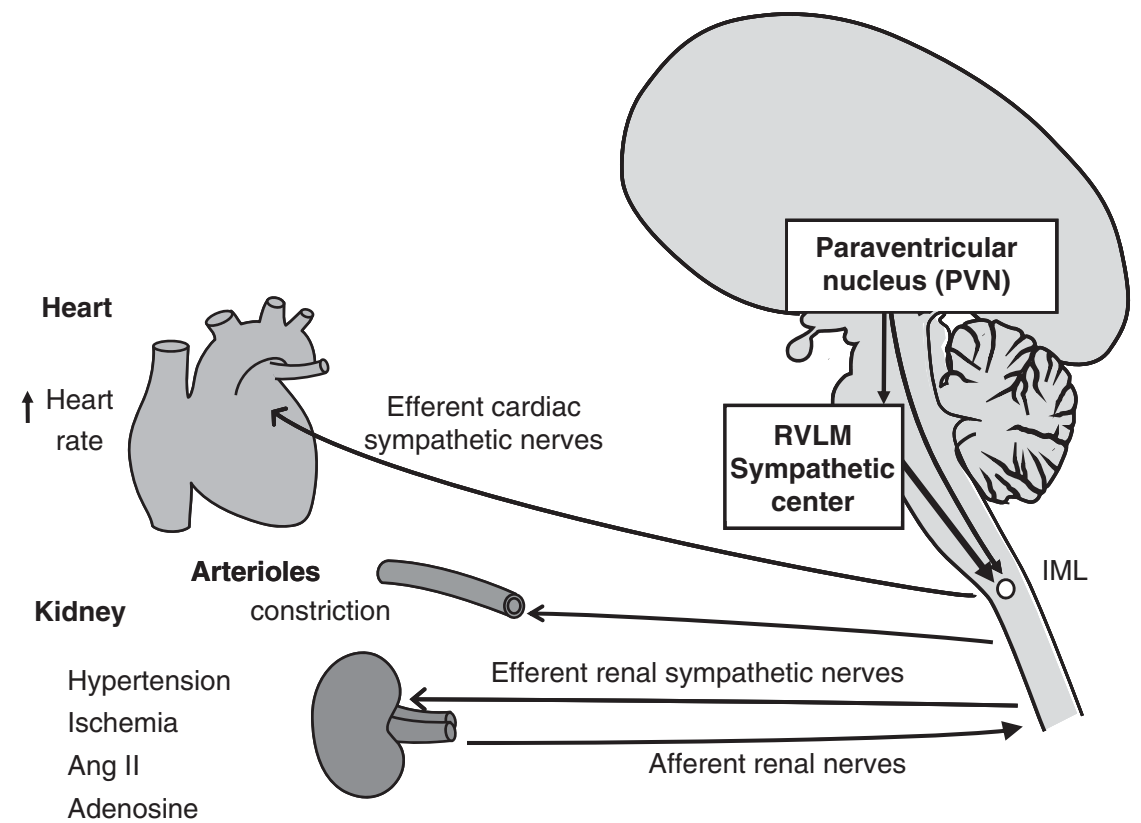

Figure 9 Updated version of the central and peripheral sympathetic nervous systems (original drawing by Kumagai). Afferent renal nerves detect information regarding the state of the kidney, such as hypertension, ischemia, angiotensin II and adenosine, and are important in the regulation of efferent sympathetic nerve activities and BP. The importance of RVLM neurons is also understood as a pivotal position in the determination of sympathetic nerve activities. A full color version of this figure is available at the Hypertension Research journal online.

the determination of efferent SNA and BP in essential hypertension and chronic kidney diseases (Figure 9).

Renal nerve ablation may be a suitable treatment for various clinical diseases. Dahl salt-sensitive rats that undergo a heminephrectomy and are fed a high-salt diet exhibit albuminuria, renal dysfunction and high activity of NADPH oxidase in the remnant kidney. Kashihara and colleagues $^{83}$ showed that 6 weeks after disruption of the renal nerves, kidney NE concentration and albuminuria were reduced and the renal function was improved.

SNA determined by NE spillover and muscle SNA is elevated in some patients with congestive heart failure ${ }^{84,85}$ Heart failure patients with high NE spillover showed a significantly worse prognosis compared with patients with normal NE spillover. ${ }^{86}$ In rats with heart failure, prior renal denervation increased natriuresis, decreased the left ventricular end diastolic pressure and improved left ventricular fractional shortening. ${ }^{87}$

Therefore, renal nerve ablation is expected to be a promising treatment for patients with hypertension, congestive heart failure and chronic kidney disease, including diabetic nephropathy, in which potentiated SNA has been implicated in the pathogenesis. ${ }^{2,3}$

\section{CONCLUSIONS}

We showed the importance of neurons in the RVLM region and a vicious cycle between the SNS and the RAS in the regulation of peripheral SNA, by using the whole-cell patch-clamp technique. The optical imaging demonstrated that a longitudinal rostro-caudal column in the ventrolateral medulla may regulate the SNS and BP. $\mathrm{ARB}$ is an appropriate tool for preventing cardiovascular events in our patients, as this drug reduces sympathetic activity both in RVLM neurons and in the periphery. For the same reason, renal nerve ablation is an encouraging therapy for patients with hypertension, congestive heart failure and chronic kidney diseases.

\section{ACKNOWLEDGEMENTS}

The research studies discussed in this review were supported by grants from the Kimura Memorial Heart Foundation for Research on the Autonomic Nervous System and Hypertension. We would like to express our sincere appreciation to Drs Carlos M Ferrario, David B Averill, Ishio Ninomiya, Hironobu Morita, Yasuhiro Nishida, Hiroshi Hosomi, Takayuki Sato, Makoto Kaneda and Toru Nabika for their kind instructions. We also thank Drs Hiromichi Suzuki, Munekazu Ryuzaki, Masashi Ichikawa, Masahiko Nishizawa and Masahito Jimbo for their vigorous effort to explore the sympathetic nervous system with us.

1 Julius S, Jamerson K. Sympathetics, insulin resistance and coronary risk in hypertension: the chicken-and-egg question. J Hypertens 1994; 12: 495-502.

2 Esler M, Lambert G, Brunner-La Rocca HP, Vaddadi G, Kaye D. Sympathetic nerve activity and neurotransmitter release in humans: translation from pathophysiology into clinical practice. Acta Physiol Scand 2003; 177: 275-284.

3 Esler M. The 2009 Carl Ludwig Lecture: pathophysiology of the human sympathetic nervous system in cardiovascular diseases: the transition from mechanisms to medical management. J Appl Physiol 2010; 108: 227-237.

4 Guyenet PG. The sympathetic control of blood pressure. Nat Rev Neurosci 2006; 7: 335-346.

5 Lucini D, Mella GS, Malliani A, Pagani M. Impairment in cardiac autonomic regulation preceding arterial hypertension in humans. Insights from spectral analysis of beat-bybeat cardiovascular vaiability. Circulation 2002; 106: 2673-2679.

6 Malpas SC. Sympathetic nervous system overactivity and its role in the development of cardiovascular disease. Physiol Rev 2010; 90: 513-557.

7 Kumagai H, Onami T, Takimoto C, ligaya K, Imai M, Matsuura T, Sakata K, Oshima N, Hayashi K, Saruta T. Involvement of renal sympathetic nerve in pathogenesis of hypertension. Kidney and blood pressure regulation. Contrib Nephrol 2004; 143: 32-45.

8 Kumagai $\mathrm{H}$, Oshima $\mathrm{N}$, Matsuura $\mathrm{T}$, Imai M, ligaya $\mathrm{K}$, Onimaru $\mathrm{H}$, Kawai A, Sakata $\mathrm{K}$, Onami T, Takimoto C, Kamayachi T, Osaka M, Hayashi K, Itoh H, Saruta T. Whole-cell patch-clamp and optical imaging of neurons in the RVLM, the CVLM, and the caudal end of VLM. In: Kubo T, Kuwaki T (eds). Central Mechanisms of Cardiovascular Regulation 2007. Transworld Research Network, Kerala, India, 2007 pp. 83-106.

9 DiBona GF, Kopp UC. Neural control of renal function. Physiol Rev 1997; 77: 75-197.

10 Pilowsky PM, Goodchild AK. Baroreceptor reflex pathways and neurotransmitters: 10 years on. J Hypertens 2002; 20: 1675-1688.

11 Sved AF, Ito S, Madden CJ. Baroreflex dependent and independent roles of the caudal ventrolateral medulla in cardiovascular regulation. Brain Res Bull2000; 15: 129-133. 
12 Mandel DA, Schreihofer AM. Glutamatergic inputs to the CVLM independent of the NTS promote tonic inhibition of sympathetic vasomotor tone in rats. Am J Physiol Heart Circ Physiol 2008; 295: H1772-H1779.

13 Mandel DA, Schreihofer AM. Modulation of the sympathetic response to acute hypoxia by the caudal ventrolateral medulla in rats. J Physiol 2009; 587: 461-475.

14 Schreihofer AM, Guyenet PG. The baroreflex and beyond: control of sympathetic vasomotor tone by GABAergic neurons in the ventrolateral medulla. Clin Exp Pharmacol Physiol 2002; 29: 514-521.

15 Schreihofer AM, Guyenet PG. Baro-activated neurons with pulse-modulated activity in the rat caudal ventrolateral medulla express GAD67 mRNA. J Neurophysiol 2003; 89: 1265-1277.

16 Kumagai H, Suzuki H, Ryuzaki M, Matsukawa S, Saruta T. Baroreflex control of renal sympathetic nerve activity is potentiated in early phase of two-kidney, one clip Goldblatt hypertension in conscious rabbits. Circ Res 1990; 67: 1309-1322.

17 Kumagai H, Averill DB, Khosla MC, Ferrario CM. Role of nitric oxide and angiotensin II in the regulation of sympathetic nerve activity in spontaneously hypertensive rats. Hypertension 1993; 21: 476-484.

18 Nishizawa M, Kumagai H, Ichikawa M, Oshima N, Suzuki H, Saruta T. Improvement in baroreflex function by an oral angiotensin receptor antagonist in rats with myocardial infarction. Hypertension 1997; 29 (Part 2): 458-463.

19 Muratani H, Averill DB, Ferrario CM. Effect of angiotensin II in ventrolateral medulla of spontaneously hypertensive rats. Am J Physiol Regul Integr Comp Physiol 1991; 260: R977-R984.

$20 \mathrm{Li}$ YW, Guyenet PG. Angiotensin II decreases a resting $\mathrm{K}^{+}$conductance in rat bulbospinal neurons of the $\mathrm{C} 1$ area. Circ Res 1996; 78: 274-282.

$21 \mathrm{Lin} \mathrm{HH}$, Wu SY, Lai CC, Dun NJ. GABA- and glycine-mediated inhibitory postsynaptic potentials in neonatal rat rostral ventrolateral medulla neurons in vitro. Neuroscience 1998; 82: 429-442.

22 Oshima N, Kumagai H, Kawai A, Sakata K, Matsuura T, Saruta T. Three types of putative presympathetic neurons in the rostral ventrolateral medulla studied with rat brainstem-spinal cord preparation. Auton Neurosci 2000; 84: 40-49.

23 Matsuura T, Kumagai H, Kawai A, Onimaru H, Imai M, Oshima N, Sakata K, Saruta T. Rostral ventrolateral medulla neurons of neonatal Wistar-Kyoto and spontaneously hypertensive rats. Hypertension 2002; 40: 560-565.

24 Matsuura T, Kumagai H, Onimaru H, Kawai A, ligaya K, Onami T, Sakata K, Oshima N, Sugaya T, Saruta T. Electrophysiological properties of rostral ventrolateral medulla neurons in angiotensin II 1a receptor knockout mice. Hypertension 2005; 46: 349354.

25 Zucker IH, Schultz HD, Patel KP, Wang W, Gao L. Regulation of central angiotensin type 1 receptors and sympathetic outflow in heart failure. Am J Physiol Heart Circ Physiol 2009; 297: H1557-H1566.

26 DiBona GF, Jones SY. Sodium intake influences hemodynamic and neural responses to angiotensin receptor blockade in rostral ventrolateral medulla. Hypertension 2001; 37: 1114-1123.

27 Tsuchihashi T, Kagiyama S, Matsumura K, Abe I, Fujishima M. Effects of chronic oral treatment with imidapril and TCV-116 on the responsiveness to angiotensin II in ventrolateral medulla of SHR. J Hypertens 1999; 17: 917-922.

28 Sumners $\mathrm{C}$, Zhu M, Gelband CH, Posner P. Angiotensin II type 1 receptor modulation of neuronal $\mathrm{K}^{+}$and $\mathrm{Ca}^{2+}$ currents: intracellular mechanisms. Am J Physiol Cell Physiol 1996; 271: C154-C163.

29 Sumners C, Fleegal MA, Zhu M. Angiotensin $\mathrm{AT}_{1}$ receptor signaling pathways in neurons. Clin Exp Pharmacol Physiol 2002; 29: 483-490.

30 Brooks VL, Osborn JW. Hormonal-sympathetic interactions in long-term regulation of arterial pressure: an hypothesis. Am J Physiol Regul Integr Comp Physiol 1995; 268: R1343-R1358.

31 Brooks VL, Haywood JR, Johnson AK. Translation of salt retention to central activation of the sympathetic nervous system in hypertension. Clin Exp Pharmacol Physiol 2005; 32: 426-432.

32 Zhang Z-H, Francis J, Weiss RM, Felder RB. The renin-angiotensin-aldosterone system excites hypothalamic paraventricular nucleus neurons in heart failure. Am J Physiol Heart Circ Physiol 2002; 283: H423-H433.

33 Dupont AG, Brouwers S. Brain angiotensin peptides regulate sympathetic tone and blood pressure. J Hypertens 2010; 28: 1599-1610.

34 Toney GM, Cato CMJ, Stocker SD. Central osmotic regulation of sympathetic nerve activity. Acta Physiol Scand 2003; 177: 43-55.

35 Chen QH, Toney GM. $\mathrm{AT}_{1}$-receptor blockade in the hypothalamic PVN reduces central hyperosmolality-induced renal sympathoexcitation. Am J Physiol Regul Integr Comp Physiol 2001; 281: R1844-R1853.

36 McKinley MJ, Johnson AK. The physiological regulation of thirst and fluid intake. News in Physiol Sci 2004; 19: 1-6.

37 Hirooka Y. Oxidative stress in the cardiovascular center has a pivotal role in the sympathetic activation in hypertension. Hypertens Res 2011; 34: 407-412.

38 Kishi T, Hirooka Y, Kimura Y, Ito K, Shimokawa H, Takeshita A. Increased reactive oxygen species in rostral ventrolateral medulla contributes to neural mechanisms of hypertension in stroke-prone spontaneously hypertensive rats. Circulation 2004; 109: 2357-2362.

39 Dai X, Cao X, Kreulen DL. Superoxide anion is elevated in sympathetic neurons in DOCA-salt hypertension via activation of NADPH oxidase. Am J Physiol Heart Circ Physiol 2006; 290: H1019-H1026.

40 Oliveira-Sales EB, Nishi EE, Carillo BA, Dolnikoff MS, Bergamaschi CT, Campos RR. Oxidative stress in the sympathetic premotor neurons contribute to sympathetic activation in renovascular hypertension. Am J Hypertens 2009; 22: 484-492.
41 Nozoe M, Hirooka Y, Koga Y, Araki S, Konno S, Kishi T, Ide T, Sunagawa K. Mitochondria-derived reactive oxygen species mediate sympathoexcitation induced by angiotensin II in the rostral ventrolateral medulla. J Hypertens 2008; 26: 2176-2184.

42 Oliveira-Sales EB, Colombari DSA, Davisson RL, Kasparov S, Hirata AE, Campos RR, Paton JFR. Kidney-induced hypertension depends on superoxide signaling in the rostral ventrolateral medulla. Hypertension 2010; 56: 290-296.

43 Kishi T, Hirooka Y, Ito K, Sakai K, Shimokawa H, Takeshita A. Cardiovascular effects of overexpression of endothelial nitric oxide synthase in the rostral ventrolateral medulla in stroke-prone spontaneously hypertensive rats. Hypertension 2002; 39: 264-268.

44 Kumagai H, Suzuki H, Ichikawa M, Nishizawa M, Oshima N, Saruta T. Interaction between endothelin and nitric oxide in sympathetic nerve modulation of hypertensive rats. Hypertens Res 1997; 20: 35-42.

45 Kimura Y, Hirooka Y, Sagara Y, Ito K, Kishi T, Shimokawa H, Takeshita A, Sunagawa K. Overexpression of inducible nitric oxide synthase in rostral ventrolateral medulla causes hypertension and sympathoexcitation via an increase in oxidative stress. Circ Res 2005: 96: 252-260.

46 Kumada M, Cao W, Kuwaki T. Effect of endothelin on vasomotor and respiratory neurons in the rostral ventrolateral medulla in rats. Cell Mol Neurobiol 2003; 23: 691-707.

47 Dampney RAL, Horiuchi J, Killinger S, Sheriff MJ, Tan PSP, McDowall LM. Long-term regulation of arterial blood pressure by hypothalamic nuclei: some critical questions. Clin Exp Pharmacol Physiol 2005; 32: 419-442.

48 Paton JFR. The ventral medullary respiratory network of the mature mouse studied in a working heart-brainstem preparation. J Physiol 1996; 493: 819-831.

49 ligaya K, Horiuchi J, McDowall LM, Dampney RAL. Topographical specificity of regulation of respiratory and renal sympathetic activity by the midbrain dorsolateral periaqueductal gray. Am J Physiol Regul Integr Comp Physiol 2010; 299: R853-R861.

50 Mashimo T, Nabika T, Matsumoto C, Tamada T, Ueno K, Sawamura M, Ikeda K, Kato N, Nara T, Yamori Y. Aging and salt-loading modulate blood pressure QTLs in rats. Am J Hypertens 1999; 12: 1098-1104.

51 Kato N, Mashimo T, Nabika T, Cui ZH, Ikeda K, Yamori Y. Genome-wide searches for blood pressure quantitative trait loci in the stroke-prone spontaneously hypertensive rat of a Japanese colony. J Hypertens 2003; 21: 295-303.

52 Kato N, Nabika T, Liang Y-Q, Mashimo T, Inomata H, Watanabe T, Yanai K, Yamori Y, Yazaki $Y$, Sasazuki T. Isolation of a chromosome 1 region affecting blood pressure and vascular disease traits in the stroke-prone rat model. Hypertension 2003; 42: 1191-1197.

53 Nabika T, Kobayashi Y, Yamori Y. Congenic rats for hypertension: how useful are they for the hunting of hypertension genes? Clin Exp Pharmacol Physiol 2000; 27: 251-256.

54 Wang T, Nabika T, Notsu Y, Takabatake T. Sympathetic regulation of the renal functions in rats reciprocally congenic for chromosome 1 blood pressure quantitative trait locus. Hypertens Res 2008; 31: 561-568.

55 Cui ZH, Ikeda K, Kawakami K, Gonda T, Masuda J, Nabika T. Exaggerated response to cold stress in a congenic strain for the quantitative trait locus for blood pressure. $J$ Hypertens 2004; 22: 2103-2109.

56 ligaya K, Kumagai H, Nabika T, Harada Y, Onimaru H, Oshima N, Takimoto C, Kamayachi T, Saruta T, Itoh $\mathrm{H}$. Relation of blood pressure quantitative trait locus on rat chromosome 1 to hyperactivity of rostral ventrolateral medulla. Hypertension 2009; 53: $42-48$.

57 Yamazato M, Ohya Y, Nakamoto M, Sakima A, Tagawa T, Harada Y, Nabika T, Takishita $\mathrm{S}$. Sympathetic hyperreactivity to air-jet stress in the chromosome 1 blood pressure quantitative trait locus congenic rats. Am J Physiol Regul Integr Comp Physiol 2006; 290: R709-R714.

58 Strack AM, Sawyer WB, Hughes JH, Platt KB, Loewy AD. A general pattern of CNS innervation of the sympathetic outflow demonstrated by transneuronal pseudorabies viral infections. Brain Res 1989; 491: 156-162.

59 Jansen AS, Wessendorf MW, Loewy AD. Transneuronal labeling of CNS neuropeptide and monoamine neurons after pseudorabies virus injections into the stellate ganglion. Brain Res 1995; 683: 1-24.

60 Matsumoto M, Takayama K, Miura M. Distribution of glutamate- and GABA-immunoreactive neurons projecting to the vasomotor center of the intermediolateral nucleus of the lower thoracic cord of Wistar rats: a double-labeling study. Neurosci Lett 1994; 174: 165-168.

61 ligaya $\mathrm{K}$, Kumagai $\mathrm{H}$, Onimaru $\mathrm{H}$, Kawai $\mathrm{A}$, Oshima $\mathrm{N}$, Takimoto $\mathrm{C}$, Kamayachi $\mathrm{T}$, Hayashi K, Saruta T, Itoh $\mathrm{H}$. Novel axonal projection from the caudal end of the ventrolateral medulla to the intermediolateral cell column. Am J Physiol Regul Integr Comp Physiol 2007; 292: R927-R936.

62 Onimaru $\mathrm{H}$, Homma I. A novel functional neuron group for respiratory rhythm generation in the ventral medulla. J Neurosci 2003; 23: 1478-1486.

63 Pilowsky P, Llewellyn-Smith IJ, Arnolda L, Inson J, Chalmers J. Intracellular recording from sympathetic preganglionic neurons in cat lumbar spinal cord. Brain Res 1994; 656: 319-328.

64 Natarajan M, Morrison SF. Sympathoexcitatory CVLM neurons mediate responses to caudal pressor area stimulation. Am J Physiol Regul Integr Comp Physiol 2000; 279: R364-R374.

65 Sun W, Panneton WM. The caudal pressor area of the rat: its precise location and projections to the ventrolateral medulla. Am J Physiol Regul Integr Comp Physiol 2002; 283: R768-R778.

66 Seyedabadi M, Li Q, Padley JR, Pilowsky PM, Goodchild AK. A novel pressor area at the medullo-cervical junction that is not dependent on the RVLM: efferent pathways and chemical mediators. J Neurosci 2006; 26: 5420-5427. 
67 Oshima N, Kumagai H, Onimaru H, Kawai A, Pilowsky PM, ligaya K, Takimoto C, Hayashi K, Saruta T, Itoh $\mathrm{H}$. Monosynaptic excitatory connection from the rostral ventrolateral medulla to sympathetic preganglionic neurons revealed by simultaneous recordings. Hypertens Res 2008; 31: 1445-1454.

68 Goldberger AL. Non-linear dynamics for clinicians: chaos theory, fractals, and complexity at the bedside. Lancet 1996; 347: 1312-1314.

69 Huikuri HV, Makikallio TH, Peng CK, Goldberger AL, Hintze U, Moller M. Fractal correlation properties of R-R interval dynamics and mortality in patients with depressed left ventricular function after an acute myocardial infarction. Circulation 2000; 101: 47-53.

70 Skinner JE, Pratt CM, Vybiral T. A reduction in the correlation dimension of heartbeat intervals precedes imminent ventricular fibrillation in human subjects. Am Heart $J$ 1993; 125: 731-743.

71 Sakata K, Kumagai H, Osaka M, Onami T, Matsuura T, Imai M, Saruta T. Potentiated sympathetic nervous and renin-angiotensin systems reduce nonlinear correlation between sympathetic activity and blood pressure in conscious spontaneously hypertensive rats. Circulation 2002; 106: 620-625.

72 Osaka M, Yambe T, Saitoh H, Yoshizawa M, Itoh T, Nitta S, Hayakawa H. Mutual information discloses relationship between hemodynamic variables in artificial heartimplanted dogs. Am J Physiol Heart Circ Physiol 1999; 275: H1419-H1433.

73 Guild S-H, Austin PC, Navakatikyan M, Ringwood JV, Malpas S. Dynamic relationship between sympathetic nerve activity and renal blood flow: a frequency domain approach. Am J Physiol Regul Integr Comp Physiol 2001; 281: R206-R212.

74 Takimoto C, Kumagai H, Osaka M, Sakata K, Onami T, Kamayachi T, ligaya K, Hayashi K, Saruta T, Itoh H. Candesartan and insulin reduce renal sympathetic nerve activity in hypertensive type 1 diabetic rats. Hypertens Res 2008; 31: 1941-1951.

75 Kasama S, Toyama T, Kumakura H, Takayama Y, Ichikawa S, Suzuki T, Kurabayashi M. Effects of candesartan on cardiac sympathetic nerve activity in patients with congestive heart failure and preserved left ventricular ejection fraction. J Am Coll Cardiol 2005; 45: 661-667.

76 Krum H, Schlaich M, Whitbourn R, Sobotka PA, Sadowski J, Bartus K, Kapelak B, Walton A, Sievert H, Thambar S, Abraham WT, Esler M. Catheter-basal renal sympathetic denervation for resistant hypertension: a multicentre safety and proof-of-principle cohort study. Lancet 2009; 373: 1275-1281.

77 Schlaich MP, Sobotka PA, Krum H, Esler M. Renal sympathetic-nerve ablation for uncontrolled hypertension. N Engl J Med 2009; 361: 932-934.
78 Symplicity HTN-2 Investigators. Renal sympathetic denervation in patients with treatment-resistant hypertension: a randomised controlled trial. Lancet 2010; 376: 1903-1909.

79 Symplicity HTN-1 Investigators. Catheter-based renal sympathetic denervation for resistant hypertension. Durability of blood pressure reduction out to 24 months. Hypertension 2011; 57: 911-917.

80 Ryuzaki M, Suzuki H, Kumagai K, Kumagai H, Ichikawa M, Matsukawa S, Matsumura Y, Saruta T. Renal nerves contribute to salt-induced hypertension in sinoaorticdenervated uninephrectomized rabbits. Am J Physiol Regul Integr Comp Physiol 1992; 62: R733-R737.

81 Ye S, Ozgur B, Campese VM. Renal afferent impulses, the posterior hypothalamus, and hypertension in rats with chronic renal failure. Kidney Int 1997; 51: 722-727.

82 Ye S, Zhong H, Duong VN, Campese VM. Losartan reduces central and peripheral sympathetic nerve activity in a rat model of neurogenic hypertension. Hypertension 2002; 39: 1101-1106.

83 Nagasu H, Satoh M, Kuwabara A, Yorimitsu D, Sakuta T, Tomita N, Kashihara N. Renal denervation reduces glomerular injury by suppressing $\mathrm{NAD}(\mathrm{P}) \mathrm{H}$ oxidase activity in Dahl salt-sensitive rats. Nephrol Dial Transplant 2010; 25: 2889-2898.

84 Hasking GJ, Esler MD, Jennings GL, Burton D, Johns JA, Korner PI. Norepinephrine spillover to plasma in patients with congestive heart failure: evidence of increased overall and cardiorenal sympathetic nervous activity. Circulation 1986; 73: 615-621.

85 Esler M, Kaye D. Sympathetic nervous system activation in essential hypertension, cardiac failure and psychosomatic heart disease. J Cardiovasc Pharmacol 2000; 35 (Suppl 4): S1-S7.

86 Petersson M, Friberg P, Eisenhofer G, Lambert G, Rundqvist B. Long-term outcome in relation to renal sympathetic activity in patients with chronic heart failure. Eur Heart $J$ 2005; 26: 906-913.

87 Nozawa T, Igawa A, Fujii N, Kato B, Yoshida N, Asanoi H, Inoue H. Effects of long-term renal sympathetic denervation on heart failure after myocardial infarction in rats. Heart Vessels 2002; 16: 51-56.

\section{(c)}

This work is licensed under the Creative Commons Attribution-NonCommercial-No Derivative Works 3.0 Unported License. To view a copy of this license, visit http://creativecommons.org/licenses/by-nc-nd/3.0 